\title{
Combustion of solid propellant with micron- sized Aluminium under the acceleration force
}

\author{
Vasily Poryazov ${ }^{1, *}$, and Dmitry Krainov ${ }^{2}$ \\ ${ }^{1}$ Tomsk State University, Department of Physics and Engineering, 634050, Russia, Tomsk, 36 Lenina \\ avenue \\ ${ }^{2}$ Tomsk Politechnical University, Institute of Power Engineering, Department of Theoretical and \\ Industrial Heat Systems Engineering, 634050, Russia, Tomsk, 30 Lenina avenue
}

\begin{abstract}
The paper presents a physical-mathematical model for metallized solid propellant combustion under acceleration directed along the normal to the burning surface. The model takes into account the thermal effect of decomposition of the condensed phase, convection, diffusion, the exothermic chemical reaction in the gas phase, heating and combustion of Al particles in the gas flow, the flow of combustion products, the particle velocity lag relative to the gas and the field effect of acceleration on the motion of $\mathrm{Al}$ particles. The effect of the $\mathrm{Al}$ particle size and mass fraction, emitted from the burning surface, on the burning rate is also taken into consideration. The impact of the Al particle size, emitted from the burning surface, on the linear burning rate has been investigated under acceleration. The study results showed that with increasing acceleration the burning rate increased. It was also revealed that the larger was the size of aluminum particles emitted from the burning surface, the higher was the response of the burning rate to acceleration. The results showed that increasing the mass fraction of aluminum in the propellant composition led to an increase in the response of the relative burning rate. It was also found that the relative burning rate sensitivity increased with pressure above the burning surface. The results obtained are in a qualitative agreement with those described in the scientific literature.
\end{abstract}

\section{Mathematical model}

The paper presents a physical-mathematical model for metallized solid propellant combustion under acceleration directed along the normal to the burning surface. The model takes into account the thermal effect of decomposition of the condensed phase, convection, diffusion, the exothermic chemical reaction in the gas phase, heating and combustion of $\mathrm{Al}$ particles in the gas flow, the flow of combustion products, and the particle velocity lag relative to the gas and acceleration forces. To model the burning out of aluminum particles in a flow of powder combustion products, we used the experimental results [1] showing that under pressures above 20 atm the rate of aluminum particle combustion in an oxidant flow do not depends on pressure, ignition of an aluminum particle occurs when it reaches a

${ }^{*}$ Corresponding author: poryazov@ftf.tsu.ru 
certain temperature. Mathematical model of solid propellant combustion with micron-sized aluminum under the acceleration forces is based on [2,3].

Under the admitted assumptions, the mathematical model is well fitted by the following equations: the energy conservation equations for the gas and aluminum particles, the mass conservation equations of the gas and particles, the particle number concentration equation, the equation of the reagent burning-out in the gas phase, the equation of particle motion in a gas flow, and the gas state equation. The system of equations written in the Cartesian axes has the following form (the origin of the coordinates is on the combustion surface):

$$
\begin{gathered}
c_{2} \rho_{2}\left(\frac{\partial T_{2}}{\partial t}+u \frac{\partial T_{2}}{\partial x}\right)=\lambda_{2} \frac{\partial^{2} T_{2}}{\partial x^{2}}+Y \rho_{2} k_{0} Q_{2} \exp \left(\frac{-E_{2}}{R_{y} T_{2}}\right)+4 \pi \alpha r_{k}^{2} n\left(T_{3}-T_{2}\right), \\
\left(\frac{\partial Y}{\partial t}+u \frac{\partial Y}{\partial x}\right)=D_{2} \frac{\partial^{2} Y}{\partial x^{2}}-Y k_{0} \exp \left(\frac{-E_{2}}{R_{y} T_{2}}\right), \\
\frac{\partial \rho_{2}}{\partial t}+\frac{\partial\left(\rho_{2} u\right)}{\partial x}=-G, \\
c_{3} \rho_{3}\left(\frac{\partial T_{3}}{\partial t}+w \frac{\partial T_{3}}{\partial x}\right)=-4 \pi \alpha r_{k}^{2} n\left(T_{3}-T_{2}\right)+G Q_{A l} \frac{2 \mu_{A l}}{3 \mu_{O}}, \\
\frac{\partial \rho_{3}}{\partial t}+\frac{\partial\left(\rho_{3} w\right)}{\partial x}=G, \\
\frac{\partial w}{\partial t}+w \frac{\partial w}{\partial x}=-\tau_{t r}-a, \\
\frac{\partial n}{\partial t}+\frac{\partial(n w)}{\partial x}=0, \\
P=\rho_{2} R T_{2}=\text { const, }
\end{gathered}
$$

Here Eqs. (1) and (4) are the energy equations for the gas phase and particles, Eqs. (2), (3), and (5) are the mass conservation equations for the gas phase, gaseous reaction products, and particles, respectively, Eq. (6) is the particle motion equation, Eq. (7) is the particle number concentration equation, and Eq. (8) is the ideal gas law.

The calculations of the $\mathrm{N}$ powder combustion were carried out under the following values of the thermophysical and kinetic parameters from [3].

According to the Belyaev-Zel'dovich model, the linear combustion rate of the powder is defined by the formula [4]: $V_{k}=K_{v} \exp \left(-E_{1} / 2 R_{y} T_{S}\right)$, where $K_{v}$ is the empirical constant.

The boundary conditions at $x=0$ are the mass and energy conservation laws:

$$
\begin{gathered}
\left(1-\alpha_{A l}\right) \rho_{1} V_{k}=\left.\rho_{2} u\right|_{x=0}, \alpha_{A l} \rho_{1} V_{k}=\left.\rho_{3} w\right|_{x=0}, \rho_{1} V_{k} Y=D_{2} \rho_{2} \partial Y /\left.\partial x\right|_{x=0}+\left.\rho_{2} u Y\right|_{x=0}, \\
\lambda_{2} \partial T /\left.\partial x\right|_{x=0}=\rho_{1} V_{k}\left(\left.c_{2} T_{2}\right|_{x=0}-Q_{1}-c_{1} T_{1,0}\right),\left.T_{3}\right|_{x=0}=\left.T_{2}\right|_{x=0}, \\
\left.\rho_{2}\right|_{x=0}=P /\left.R T_{2}\right|_{x=0},\left.n\right|_{x=0}=\left.\rho_{3}\right|_{x=0} /(4 / 3) \pi r_{A l, 0}^{3} \rho_{k}, P=\text { const } .
\end{gathered}
$$

The following boundary conditions are specified on the boundary $x=\infty$ :

$$
\partial T /\left.\partial x\right|_{x=\infty}=0, \partial Y /\left.\partial x\right|_{x=\infty}=0 .
$$

Here $r_{A l, 0}$ is the radius of an aluminum particle coming out from the $\mathrm{N}$ powder combustion surface into the gas flow and $T_{1,0}$ is the initial temperature of the powder, $\left.T_{2}\right|_{x=0} \equiv T_{S}$.

The initial conditions: 


$$
\begin{gathered}
T_{2}(x, 0)=T_{i g n}, T_{3}(x, 0)=T_{i g n}, Y(x, 0)=0, \\
\rho_{2}(x, 0)=P / R T_{2}(x, 0), \rho_{3}(x, 0)=0, w(x, 0)=0, n(x, 0)=0 .
\end{gathered}
$$

The particle interaction force with the gas is defined by the formula:

$$
\tau_{t r}=F_{t r} / 4 / 3 \pi r_{k}{ }^{3} \rho_{k}{ }^{\prime}, F_{t r}=C_{R} S_{m} \rho_{2}(w-u)|u-w| / 2,
$$

where $S_{m}$ is the midsection area; $F_{t r}$ is the drag force of a sphere; and $C_{R}$ is the drag coefficient.

According to the empirical formula [5], the drag coefficient is:

$$
C_{R}=24\left(1+0,15 \operatorname{Re}^{0,682}\right) / \operatorname{Re}, \operatorname{Re}=2 r_{k} \rho_{2}|u-w| / \eta,
$$

where $\eta$ is the dynamic viscosity coefficient.

The heat transfer coefficient is equal [6]:

$$
\alpha=\frac{N u \lambda_{2}}{2 r_{k}}, N u=2+\sqrt{N u_{l}^{2}+N u_{t}^{2}},
$$

where $N u_{l}=0,664 \mathrm{Re}^{0,5}, N u_{t}=0,037 \mathrm{Re}^{0,8}, N u$ - Nusselt number.

The mass change rate of a particle during the combustion is determined as in [3]:

$$
G=\frac{3 \mu_{O}}{2 \mu_{A l}} n \rho_{k} 4 \pi r_{A l}^{1.5} k_{A l} a_{o x}{ }^{0.9}, k_{A l}=2.22 \cdot 10^{-5} \mathcal{M}^{1.5} / c,
$$

The radius of unburnt aluminum particle $r_{A l}$ is:

$$
r_{A l}=\left[\left(\left(1+3 \mu_{O} / 2 \mu_{A l}\right) r_{A l, 0}^{3}-\rho_{3} /(4 / 3) \pi n \rho_{k}\right)^{2} \mu_{A l} / 3 \mu_{O}\right]^{1 / 3} \text {. }
$$

We investigated the influence of acceleration forces on the combustion rate of $\mathrm{N}$ powder with micron-size aluminum particles. The acceleration, particle radius and pressure in the calculations ranged from $-50 \mathrm{~g}$ to $50 \mathrm{~g}$, from 1 to $30 \mu \mathrm{m}$, and from 20 to $100 \mathrm{~atm}$, respectively. The aluminum mass concentration was equal to $9 \%$. Pic. 1 shows the calculations result of combustion rate depending on acceleration forces directed along the normal to the burning surface.

Research of dependance of non-dimensional quantity $U$ on aceleration value $a$, where $U=V_{k} / V_{k, 0}, V_{k}$ is the combustion rate at specified value of accelaration, and $V_{k, o}$ is the combustion rate without accelaration, calculated under each value of pressure and different aluminum dispersity. Actually, the resalt provides relative velocity gain with rising acceleration for each composition under set pressure near the combustion surface.

This dependaces are of some practical interest.

As Pic. 1 shows, the more acceleration rises, the more combustion rate changes. The increase of $\mathrm{Al}$ particle size leads to the rising of relative velocity gain at the same acceleration value. 


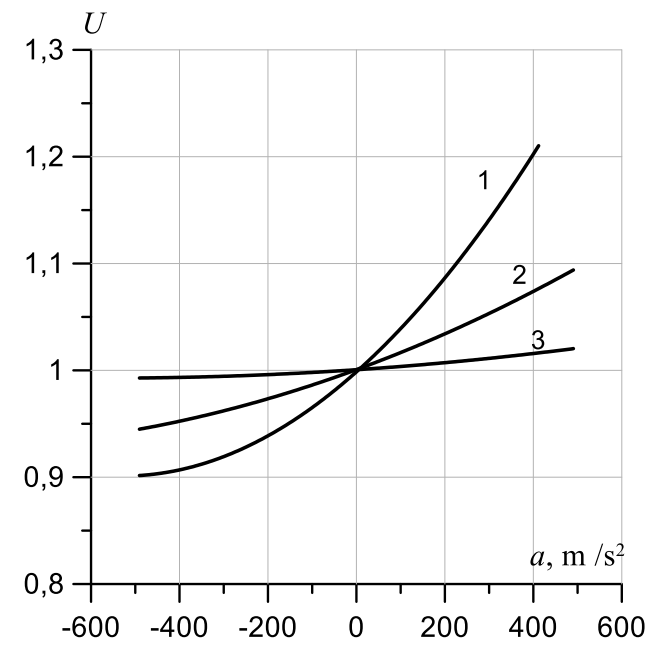

Fig. 1. The $\mathrm{N}$ powder combustion rate - acceleration curves for different Al particle size $r_{A l, 0}$. $P=40 \mathrm{~atm} .1-r_{A l, 0}=15 \mu \mathrm{m}, 2-r_{A l, 0}=10 \mu \mathrm{m}, 3-r_{A l, 0}=5 \mu \mathrm{m}$

The combustion rate at certain aceleration value grows more significantly at high pressure. Thus we observe the increase of relative velocity gain near the combustion surface.

The growth of $\mathrm{Al}$ mass concentration up to $20 \%$ of propellant resulting in the rising of the combustion rate at the same acceleration values.

The reaserch showed that the combustion rate of solid propellant under acceleration forces directed along the normal to the burning surface increases due to the presence of $\mathrm{Al}$ particles which stay close to the combustion surface during the acceleration. The Al particle burning increases the gas temperature along the powder surface, the conductive heat flux grows, the temperature of powder surface rises, and therefore linear combustion rate of the propellant goes up. The obtained results are in a qualitative agreement with those described in the scientific literature.

This work was carried out with financial support from President of Russian Federation grant MK1763.2017.8.

\section{References}

1. A.F. Belyaev, Yu.V. Frolov, A.I. Korotkov, Combust., Explosion and Shock Waves 4, 182 (1968)

2. Ya.B. Zel'dovich, J. Exp. Theoret. Phys. 12, 498 (1942) [in Russian]

3. V.A. Poryazov, A.Yu. Krainov, D.A. Krainov, J. Eng. Phys. Thermophys. 88, 94 (2015)

4. A.Yu. Krainov, V.A. Poryazov, Combust., Explosion and Shock Waves 52, 177 (2016).

5. Spravochnik po teploobmennikam. V dvukh tomakh. V.1. $\mathrm{M}$ : Energoatomizdat, 1987. [in Russian]

6. A.F. Belyayev, Goreniye, detonatsiya i rabota vzryva kondensirovannykh system, Moscow, Nauka, 1968 [in Russian] 